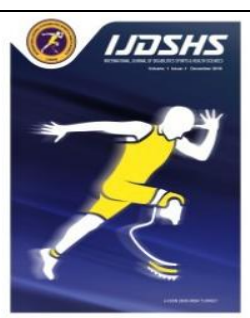

\title{
The Effectiveness of Telerehabilitation-Based Occupational Therapy Interventions on Sensory Processing and Functional Independence in the COVID-19 Pandemic: A Case Series
}

\author{
Güleser GÜNEY YILMAZ* ${ }^{1}$ and Gözde ÖNAL ${ }^{2}$ (D) \\ ${ }^{* 1}$ Kütahya Health Science University, Therapy and Rehabilitation Department, Kütahya, Turkey \\ ${ }^{2}$ Nevşehir Hacı Bektaş Veli University, Therapy and Rehabilitation Department, Nevşehir, Turkey \\ *Corresponding author: guleser.guney.gg@gmail.com
}

\begin{abstract}
Our study aimed to determine the effectiveness of telerehabilitation-based occupational therapy interventions on the level of sensory processing and functional independence during the pandemic period. Five children between the ages of 5 and 7 with sensory integration disorders were included in our study. A total of 16 sessions of telerehabilitation, 8 weeks, 2 sessions per week, were carried out via online channels (Zoom/Skype). Dunn Sensory Profile and WeeFIM Functional Independence Measure were applied before and after treatment. Data before and after the session were compared with SPSS 23.00. As a result, positive effects of telerehabilitation interventions on visual, vestibular, tactile and multi-sensory processing and functional activity level were determined in children $(\mathrm{p}<0.05)$. In conditions that negatively affect face-to-face rehabilitation, such as a pandemic, telerehabilitation interventions can be safe and alternative approaches. More telerehabilitation researchs are needed in the field of occupational therapy.
\end{abstract}

Keywords

Telerehabilitation, Sensory İntegration, Pandemic, Functional İndependence, Occupational Therapy

\section{INTRODUCTION}

Telerehabilitation is a new and developing area of telehealth (Cason, Hartmann, \& Richmond, 2018). Telerehabilitation is a service model that provides remote treatment services using various telecommunication technologies and is an alternative to face-to-face rehabilitation (Sarsak, 2020). Telerehabilitation services include monitoring, intervention, supervision, education, training, and counseling (Schmeler et al., 2010). The telerehabilitation practices used by occupational therapists can be used to develop skills, change work, home or school environments, and create health-enhancing habits and routines (Torpil \& Kaya, 2021; Önal, Güney, Gün \& Huri, 2021).
Among the alternative service delivery methods, telerehabilitation applications are frequently used in occupational therapy. Occupational therapists use telerehabilitation to develop skills; include assistive technology and adaptive techniques; change work, home or school environments and to create health-improving habits and routines. Telerehabilitation is useful because it improves accessibility of services and access to specialists, increases flexibility of treatment times for patients and therapists, reduces travel time and reduces delays in service by allowing online consultation (Johnston, 2019).

Access to rehabilitation centers is not always easy for children with special needs living in rural areas, $r$ there may not be permanent occupational therapy in every school with children with special needs. Telehealth technologies are an alternative 
when access to face-to-face rehabilitation is limited. The requirements for telerehabilitation applications have become clearer, especially with the introduction of special conditions such as pandemics into our lives (Önal, Güney, Gün, \& Huri, 2021).

Ayres (Roley, Mailloux, Miller-Kuhaneck, \& Glennon, 2007) defines sensory integration as a neurological process that organizes sensory stimuli from the body and the environment so that the body can be used more effectively. Sensory processing disorder affects the person's participation in activities of daily living (Bodison \& Parham, 2018). It is important to increase participation in order to maintain the well-being of the person. In order to maintain participation, occupational therapists frequently apply sensory integration-based approaches (Kashefimehr, 2014).

With the entry of COVID-19 into our lives, rehabilitation processes have been interrupted. However, the support needs of children with special needs continue to increase (Önal, Güney, \& Huri, 2021).

This study aimed to investigate the effects of telerehabilitation-based occupational therapy interventions on sensory processing and functional independence level in children who had disruptions in rehabilitation processes during the pandemic process.

\section{MATERIALS AND METHODS}

\section{Participants:}

The necessary permission and approval were obtained from the Ministry of Health of the Republic of Turkey for the study to be performed (File no: 29T16_18_46). In addition, informed consent was obtained from the families of the children with special needs participating in the study.

A study invitation was prepared to inform families about telerehabilitation and sensory integration-based occupational therapy; It has been stated that the children will be evaluated through Google forms or e-mail and the interviews will be held over Zoom/Skype. The families were clearly informed that they could leave the study if they wanted to and that their personal data would be kept confidential. The invitation containing the research content, purpose and method was shared through online channels. Informed consent forms were signed by parents and sent to the researchers via online channels. Five children with sensory integration disorder between the ages of 5-7 were included in our study. Three of these children were diagnosed with autism spectrum disorder, one with attention deficit and one with attention deficit and hyperactivity disorder. A total of 16 sessions of telerehabilitation, 8 weeks, 2 sessions per week, were carried out via online channels (Zoom/Skype). Dunn Sensory Profile and WeeFIM Functional Independence Measure were applied before and after treatment. Evaluation forms were sent to families as Google Forms. Data before and after the session were compared with SPSS 23.00 (Wilcoxon Signed Ranked Test).

\section{The Functional Independence Measurement for Children (WeeFIM)}

The WeeFIM is used to evaluate functional independence in children aged 6 months to 7 years, regardless of disability level (Wong, Au-Yeung, \& Law, 2005). It consists of 18 items divided into 6 subsections (self-care, sphincter control, transfer, locomotion, communication, social cognition). In the scale filled out by the parents, the child scores between 1 (full help) and 7 (completely independent) from each sub-item (Ottenbacher et al., 2000). The scores that can be obtained from the scale vary between 18 and 126. A high score indicates that functional independence is high in daily life (Chan, \& Wong, 2002). In a study conducted to translate the WeeFIM into Turkish Cronbach's $\alpha$ value was 0.99 for motor WeeFIM rating and 0.99 for cognitive WeeFIM rating. ICC was 0.81 for motor WeeFIM rating and 0.92 for cognitive WeeFIM rating. The internal construct validity of the Turkish translation of the WeeFIM instrument was confirmed by excellent fit to the Rasch measurement model (Aybay et al., 2007).

\section{The Sensory Profile}

This scale can be used for all children between the ages of 3 and 10, regardless of disability group and degree of exposure. It is evaluated by the occupational therapist together with the person with whom the child has the most communication in daily life. Each item is scored between 1 and 5 on a Likert scale. The sensory profile consists of three parts as sensory processing, processing, behavioral-emotional responses and 14 parameters. Parents or caregivers are asked to answer the 125 questions of the SP that draw up their child's sensory profile in three main domains, including sensory processing, behavioral, and emotional responses and 
processing, and also nine factors, including endurance/tone, oral sensory sensitivity, inattention/distractibility, poor registration, sensory sensitivity, sedentary, and fine motor/perceptual (Dunn, 1999). In a study conducted to translate the SP into Turkish (Kayihan et al., 2015), Cronbach's $\alpha$ values ranged from .63 to .97 , and a high one-week test-retest reliability was found [ICC] > .90).

\section{Intervention}

The contents and materials of the sessions, which were individually prepared within the scope of the intervention program, were sent to the families via e-mail. Phone calls were made before each session so that the families could obtain the necessary materials and apply the sensory activities in the session correctly. The contents of the sessions were planned considering the individual needs of the children and the family's access to resources. In the intervention program, the individual needs of the children were taken into account. For example, it was supported by visual-sensory-based activities in children with visual seeking. Each session lasted approximately 45-60 minutes. Occupational therapy practices were carried out with the cooperation of familytherapist and child, with therapist guidance sensory seeking, emotional reaction, low through online interviews (Zoom/Skype) during the sessions. If the child was distracted, the session was interrupted.

\section{Data Analysis}

Statistical analyses were performed using SPSS software version 23.00. Descriptive statistics were used for demographic data. Descriptive analyses were presented using the mean and standard deviation and frequencies. Data before and after the session were compared with SPSS 23.00 (Wilcoxon Signed Ranked Test).

\section{RESULTS}

\section{Findings of Functional Independence}

According to the results of the Functional Independence Measure for Children (the WeeFIM), it was determined that the children had improvements in the areas of self-care, transfer from one place to another, social cognition and total functional independence after telerehabilitation-based occupational therapy intervention (Table 1).

Table 1: The changes in functional independence

\begin{tabular}{lcccc}
\hline \multirow{2}{*}{ WEEFIM } & $\mathbf{B R}$ & AR & \\
\cline { 2 - 5 } & $\mathrm{X} \pm \mathrm{SD}$ & $\mathrm{X} \pm \mathrm{SD}$ & $\mathrm{p}$ & $\mathrm{Z}$ \\
\hline Selfcare & $13.2 \pm 2.16$ & $28.80 \pm 9.09$ & $0.043^{*}$ & -2.023 \\
\hline Sphincter Control & $11.8 \pm 1.48$ & $12.40 \pm 1.67$ & 0.180 & -1.342 \\
\hline Transfers & $14.8 \pm 2.38$ & $17.20 \pm 2.67$ & $0.039^{*}$ & -2.060 \\
\hline Locomotion & $11.80 \pm 2.38$ & $12.40 \pm 2.63$ & 0.083 & -1.732 \\
\hline Communication & $8.80 \pm 1.92$ & $10.00 \pm 2$ & 0.063 & -1.857 \\
\hline Tocial Cognition & $6.60 \pm 2.19$ & $12.60 \pm 2.70$ & $0.042^{*}$ & -2.032 \\
\hline
\end{tabular}

$\mathrm{p}<0.05^{*}$; AR:After Telerehabilitation; BR: Before Telerehabilitation; $\mathrm{X} \pm \mathrm{SD}:$ Mean \pm Standard Deviation;

\section{Findings on Sensory Processing}

According to Dunn Sensory Profile results, visual, vestibular, tactile and multisensorial processes were improved before and after the intervention. While children's visual, vestibular, tactile and multisensory processing processes definitely different before the intervention compared to their peers, their visual, tactile and multisensory processing levels approached the level of their peers after the intervention. Vestibular processing levels were still at the level of definite difference compared to their peers. The changes in the sensory processing processes of the cases after the occupational therapy intervention are shown in Table 2. 
Table 2: Changes in sensory processing processes of cases

\begin{tabular}{lcccc}
\hline \multirow{2}{*}{ Sensory Processing } & Before Telerehabilitation & After Telerehabilitation & \\
\cline { 2 - 5 } & $\mathrm{X} \pm \mathrm{SD}$ & $\mathrm{X} \pm \mathrm{SD}$ & $\mathrm{p}$ & $\mathrm{Z}$ \\
\hline Visual & $23.40 \pm 2.40$ & $30.80 \pm 2.38$ & $0.041^{*}$ & $-2,032$ \\
Vestibular & $13.80 \pm 1.48$ & $32.60 \pm 7.26$ & $0.032 *$ & $-2,021$ \\
Tactile & $30 \pm 7.21$ & $65.40 \pm 5.54$ & $0.043 *$ & $-2,023$ \\
Multisensorial & $10.60 \pm 2.79$ & $25.80 \pm 1.78$ & $0.039 *$ & $-2,013$ \\
\hline
\end{tabular}

$\mathrm{p}<0.05^{*} ; \mathrm{X} \pm \mathrm{SD}: \mathrm{Mean} \pm$ Standard Deviation; Gray: Typical Performance; Yellow: Probable difference; Orange: Definite difference

\section{DISCUSSION}

In the current study, which investigated the effects of telerehabilitation-based occupational therapy interventions on sensory processing and functional independence during the pandemic process, significant changes were determined in children's visual, vestibular, tactile and multisensory processing and functional independence levels.

One of the most important factors affecting participation in activities of daily living is sensory processing skills. Sensory processing disorders affect individuals' participation in activities of daily living. Occupational therapists use specific sensory modalities for self-regulation, attention and behavioral control (Önal, \& Güney Y1lmaz , 2021). In the current study, positive gains were obtained in both sensory processing processes and performance levels in activities of daily living. Well-regulated and properly functioning sensory systems contribute to important outcomes in the development and maintenance of social-emotional, motor, communication, cognitive and self-care skills (AOTA, 2015). The achievements of children in sensory processing processes through telerehabilitation may also have positively affected their level of independence in functional activities. Similarly, it has been shown that sensory-based telerehabilitation studies applied to children with special needs lead to improvements in adaptive skills, social interaction skills and activity participation (Hung \& Fong, 2019; Önal, Güney, Gün\& Huri, 2021).

Telerehabilitation provides the therapist with the opportunity to observe parent-child interaction in the home environment and provide meaningful and real-time feedback (Gibbs \& Toth-Cohen, 2011). Home programs are often used by occupational therapists to support rehabilitation processes (Novak et al., 2013). The use of telerehabilitation revealed that parents needed constant support. Therapists should not assume that in-clinical training will automatically result in appropriate transfer to demonstrate appropriate techniques and strategies in the natural setting. Thus, it can provide much-needed guidance without requiring additional clinic visits (Marshall, Shaw, Honles, \& Sparks, 2008). The therapistsupervised sessions also ensured that the errors that may arise during the application are intervened at the right time. Families often complain about the inability to ensure continuity in implementing home programs. In pandemic conditions where access to face-to-face rehabilitation is limited, children have gained the opportunity to attend regular therapist-supervised sessions through telerehabilitation.

Correct motor movement and good function emerge with a meaningful-purpose sensory activity specific to each child (Niutanen, Harra, Lano, \& Metsäranta, 2020). The sensory enriched environment and materials organized by occupational therapists help improve children's activity performance (Cheung, \& Lau, 2020; Piwinski, Hoss, Velasco, \& Jess, 2021). The session materials, which are created specifically for the individual and developed every week according to the child's progress level, revealed positive results in providing the sensory regulation of the children in the home environment. In addition, it is thought that the progress of children's sensory processing processes is associated with positive developments, especially in self-care activities and social communication levels. On the other hand, although statistically positive developments were achieved regarding the level of vestibular processing, clinical significance was still not achieved. At this point, it should be investigated whether session times or non-clinical 
session environments are insufficient to support the vestibular system.

Telerehabilitation applications are quite new areas in rehabilitation in our country (Ceylan, 2020). Therefore, discussions about its applicability and effectiveness still continue (Önal, Güney, Gün, \& Huri, 2021). Some limitations emerged in the current study as well. Some families with limited Internet access have had difficulty participating in telerehabilitation. At the same time, families who needed financial resources to access the sensory materials required for rehabilitation were not included in the study. During the sessions with the families, the parents had difficulty in understanding some of the instructions. As a result, in the current study carried out with sensory-based occupational therapy telerehabilitation interventions in the COVID-19 pandemic, it has been an alternative and useful method for disrupted rehabilitation processes. Further randomized controlled trials involving more children may contribute to the literature.

\section{Acknowledgement}

The authors express their gratitude to all families and children who participated in the study.

\section{Conflict of interests}

The authors have no conflict of interests to declare. No financial support was received for this study.

\section{Ethics Statement}

The necessary permission and approval were obtained from the Ministry of Health of the Republic of Turkey for the study to be performed (File no: 29T16_18_46). In addition, informed consent was obtained from the families of the children with special needs participating in the study.

\section{REFERENCES}

Aybay C, Erkin G, Elhan AH, Sirzai H, Ozel S (2007). ADL assessment of nondisabled Turkish children with the WeeFIM instrument. Am $J$ Phys Med Rehabil; 86:176-182.

Bodison, S. C., \& Parham, L. D. (2018). Specific sensory techniques and sensory environmental modifications for children and youth with sensory integration difficulties: A systematic review. American Journal of
Occupational Therapy,

72(1), 7201190040p1-7201190040p11.

Ceylan, A. The COVID-19 Process and Telerehabilitation Applications in Physiotherapy: Review. Adnan Menderes University Faculty of Health Sciences Journal, 5(3), 617-627.

Cheung, P. P. P., \& Lau, B. W. M. (2020). Neurobiology of sensory processing in autism spectrum disorder. Progress in Molecular Biology and Translational Science, 173, 161-181.

Dunn, W. (1999). Sensory Profile. San Antonio. Texas: Psicological Corporation.

Gibbs, V., \& Toth-Cohen, S. (2011). Familycentered occupational therapy and telerehabilitation for children with autism spectrum disorders. Occupational Therapy in Health Care, 25(4), 298-314.

,Hung, K. N, \& Fong, K. N. (2019). Effects of telerehabilitation in occupational therapy practice: A systematic review. Hong Kong Journal of Occupational Therapy, 32(1), 321.

J Jana Cason, D. H. S., Kim Hartmann PhD, O. T. R., \& Tammy Richmond, M. S. (2018). Telehealth in Occupational Therapy. The American Journal of Occupational Therapy, 72, 1-18.

Johnston, R. (2019). Caregiver Perspectives on Telehealth: A Service Delivery for Occupational Therapy.

Kashefimehr, B. (2014). Investigation of sensory perception integration therapy according to Moho model in children with autism spectrum disorder.

Kayihan, H., Akel, B. S., Salar, S., Huri, M., Karahan, S., Turker, D., \& Korkem, D. (2015). Development of a Turkish version of the sensory profile: translation, cross-cultural adaptation, and psychometric validation. Perceptual and Motor Skills, 120(3), 971986.

Marshall, S. G., Shaw, D. K., Honles, G. L., \& Sparks, K. E. (2008). Interdisciplinary approach to the rehabilitation of an 18-yearold patient with bronchopulmonary dysplasia, using telerehabilitation technology. Respiratory Care, 53(3), 346350.

Mori, A. B. (2015). Addressing sensory integration and sensory processing disorders across the 
lifespan: The role of occupational therapy. American Occupational Therapy Association.

Niutanen, U., Harra, T., Lano, A., \& Metsäranta, M. (2020). Systematic review of sensory processing in preterm children reveals abnormal sensory modulation, somatosensory processing and sensory-based motor processing. Acta Paediatrica, 109(1), 45-55.

Novak, I., \& Berry, J. (2014). Home program intervention effectiveness evidence. Physical \& Occupational therapy in Pediatrics, 34(4), 384-389.

Ottenbacher, K. J., Msall, M. E., Lyon, N., Duffy, L. C., Ziviani, J., Granger, C. V., ... \& Feidler, R. C. (2000). The WeeFIM instrument: its utility in detecting change in children with developmental disabilities. Archives of Physical Medicine and Rehabilitation, 81(10), 1317-1326.

Önal, G., Güney, G., Gün, F., \& Huri, M. (2021). Telehealth in paediatric occupational therapy: a scoping review. International Journal of Therapy And Rehabilitation, 28(7), 1-16.

Önal, G., Güney, G., \& Huri, M. (2021). Quality of life and occupational performance of children with cancer in the era of the COVID-19 pandemic in terms of rehabilitation. Quality of Life Research, 112.

Önal, G., \& Güney Y1lmaz, G. (2021). Optik Disk Hipoplazili Bir Çocukta Kanada Okupasyonel Perfomans Modeli'ne Göre Ergoterapi Müdahalesinin Etkinliğinin İncelenmesi: Olgu Çalışması. Journal of Social Research and Behavioral Sciences, 7(13).

Piwinski, N., Hoss, J., Velasco, R., \& Jess, V. (2021). Relationship Between Sensory Integration and Occupational Participation for School-Aged Children.

Sarsak, H. I. (2020). Telerehabilitation services: a successful paradigm for occupational therapy clinical services. Int Phys Med Rehabil J, 5(2), 93-98.
Schaaf, R. C., Dumont, R. L., Arbesman, M., \& May-Benson, T. A. (2018). Efficacy of occupational therapy using Ayres Sensory Integration ${ }^{\circledR}$ : A systematic review. American Journal of Occupational Therapy, 72(1), 7201190010p1-7201190010p10.

Smith Roley, S., Mailloux, Z., Miller-Kuhaneck, H., \& Glennon, T. (2007). Understanding Ayres' sensory integration.

Torpil, B., \& Kaya, Ö. (2021). The effectiveness of client-centered intervention with telerehabilitation method after total knee arthroplasty. OTJR: Occupation, Participation and Health, 15394492211038293.

Wong, V., Au-Yeung, Y. C. T., \& Law, P. K. (2005). Correlation of Functional Independence Measure for Children (WeeFIM) with developmental language tests in children with developmental delay. Journal of Child Neurology, 20(7), 613-616.

Wong, V., Wong, S., Chan, K., \& Wong, W. (2002). Functional independence measure (WeeFIM) for Chinese children: Hong Kong cohort. Pediatrics, 109(2), e36-e36.

Wuang, Y. P., Ho, G. S., \& Su, C. Y. (2013). Occupational therapy home program for children with intellectual disabilities: a randomized, controlled trial. Research in Developmental Disabilities, 34(1), 528-537.

How to cite this article: Güney Yılmaz, G., and Önal, G. (2021). The Effectiveness of Telerehabilitation-Based Occupational Therapy Interventions on Sensory Processing and Functional Independence in the COVID19 Pandemic: A Case Series. Int J Disabil Sports Health Sci; 4(2):160-165.https: //doi.org/10.3343 /ijdshs. 1008690 